\title{
Influence of Primary Gage Sensitivities on the Convergence of Balance Load Iterations
}

\author{
N. Ulbrich* \\ Jacobs Technology Inc., Moffett Field, California 94035-1000
}

\begin{abstract}
The connection between the convergence of wind tunnel balance load iterations and the existence of the primary gage sensitivities of a balance is discussed. First, basic elements of two load iteration equations that the iterative method uses in combination with results of a calibration data analysis for the prediction of balance loads are reviewed. Then, the connection between the primary gage sensitivities, the load format, the gage output format, and the convergence characteristics of the load iteration equation choices is investigated. A new criterion is also introduced that may be used to objectively determine if the primary gage sensitivity of a balance gage exists. Then, it is shown that both load iteration equations will converge as long as a suitable regression model is used for the analysis of the balance calibration data, the combined influence of non-linear terms of the regression model is very small, and the primary gage sensitivities of all balance gages exist. The last requirement is fulfilled, e.g., if force balance calibration data is analyzed in force balance format. Finally, it is demonstrated that only one of the two load iteration equation choices, i.e., the iteration equation used by the primary load iteration method, converges if one or more primary gage sensitivities are missing. This situation may occur, e.g., if force balance calibration data is analyzed in direct-read format using the original gage outputs. Data from the calibration of a six-component force balance is used to illustrate the connection between the convergence of the load iteration equation choices and the existence of the primary gage sensitivities.
\end{abstract}

\section{Nomenclature}

\begin{tabular}{|c|c|}
\hline$A F$ & $=$ axial force \\
\hline$b 1, b 2$ & $=$ coefficient of the regression model of a gage output, defined in Ref. [1], Eq. (3.1.3) \\
\hline $\mathbf{B}_{1}$ & $=$ square matrix; consists of linear terms that are on the principal diagonal of $\mathbf{C}$ \\
\hline $\mathbf{B}_{2}$ & $=$ square matrix; consists of linear terms that are not on the principal diagonal of $\mathbf{C}$ \\
\hline$c 1, c 2, \cdots, c 6$ & $=$ coefficient of the regression model of a gage output, defined in Ref. [1], Eq. (3.1.3) \\
\hline $\mathbf{C}$ & $=$ regression coefficient matrix; saves regression coefficients of fitted gage outputs \\
\hline $\mathbf{C}_{1}$ & $=$ square matrix; consists of linear terms of matrix $\mathbf{C}$ \\
\hline $\mathbf{C}_{2}$ & $=$ rectangular matrix; consists of absolute value and non-linear terms of matrix $\mathbf{C}$ \\
\hline$d 1, d 2$ & $=$ coefficient of the regression model of a gage output, defined in Ref. [1], Eq. (3.1.3) \\
\hline $\mathbf{F}$ & $=$ part of matrix $\mathbf{G}$ that consists of loads \\
\hline G & $=$ load matrix; saves regressors used for the least squares fit of gage outputs \\
\hline $\mathbf{H}$ & $=$ part of matrix $\mathbf{G}$ that consists of absolute value and non-linear terms \\
\hline$i$ & $=$ index of a gage output - or- index of a primary gage load \\
\hline & $=$ index of a load component \\
\hline$k$ & $=$ index of a load component \\
\hline K & $=$ capacity of a primary gage load of a balance \\
\hline & $=$ number of load components of a balance \\
\hline$N F$ & $=$ total normal force \\
\hline
\end{tabular}

* Aerodynamicist, Jacobs Technology Inc. 


\begin{tabular}{|c|c|}
\hline$N 1$ & $=$ normal force at the forward normal force gage of the balance \\
\hline$N 2$ & $=$ normal force at the aft normal force gage of the balance \\
\hline$p$ & $=$ distance between the normal force gages of the balance \\
\hline$P$ & $=$ percent contribution of a coefficient of the regression model of a gage output \\
\hline$P M$ & $=$ total pitching moment at the balance moment center \\
\hline$P M 1$ & $=$ pitching moment at the forward pitching moment gage of the balance \\
\hline PM2 & $=$ pitching moment at the aft pitching moment gage of the balance \\
\hline & $=$ distance between the side force gages of the balance \\
\hline$\Delta \mathbf{R}$ & $=$ strain-gage output difference vector \\
\hline$R 1$ & $=$ output of the forward normal force gage \\
\hline $\mathcal{R} 1$ & $=$ output of the forward pitching moment gage \\
\hline$R 2$ & $=$ output of the aft normal force gage \\
\hline $\mathcal{R} 2$ & $=$ output of the aft pitching moment gage \\
\hline$R 3$ & $=$ output of the forward side force gage \\
\hline $\mathcal{R} 3$ & $=$ output of the forward yawing moment gage \\
\hline$R 4$ & $=$ output of the aft side force gage \\
\hline $\mathcal{R} 4$ & $=$ output of the aft yawing moment gage \\
\hline$R 5, \mathcal{R} 5$ & $=$ output of the rolling moment gage \\
\hline$R 6, \mathcal{R} 6$ & $=$ output of the axial force gage \\
\hline$R 1^{\prime}, R 2^{\prime}, \cdots, R 6^{\prime}$ & $=$ transformed gage outputs \\
\hline$R M$ & $=$ rolling moment \\
\hline$S F$ & $=$ total side force \\
\hline$S 1$ & $=$ side force at the forward side force gage of the balance \\
\hline$S 2$ & $=$ side force at the aft side force gage of the balance \\
\hline$Y M$ & $=$ total yawing moment \\
\hline$Y M 1$ & $=$ yawing moment at the forward yawing moment gage of the balance \\
\hline$Y M 2$ & $=$ yawing moment at the aft yawing moment gage of the balance \\
\hline & $=$ iteration step index \\
\hline
\end{tabular}

\section{Introduction}

Different approaches are used in wind tunnel testing to predict wind tunnel balance loads from the measured electrical output of strain-gages. The so-called Iterative Method is often selected because it closely follows the experimental approach that is used to calibrate a strain-gage balance. The Iterative Method derives a regression model from calibration data such that the calibration loads are treated as "applied" or "independent" variables and the strain-gage outputs are treated as "measured" or "dependent" variables. Therefore, as loads are the "independent" variables of the regression analysis problem, load iterations have to be performed so that loads can be predicted from the measured gage outputs during a wind tunnel test (see Refs. [1] and [2] for a detailed discussion of the Iterative Method and the load iteration process).

The balance load iterations may or may not converge depending on (i) the quality and format of the original calibration data set and (ii) the regression model of the gage outputs. Therefore, it is critical to understand factors that influence the convergence characteristics of the load iterations in order to prevent a divergence of the iterations during calibration data analysis and wind tunnel test applications.

Four major factors are known to influence the convergence characteristics of the load iteration scheme that the Iterative Method uses for the prediction of balance loads from measured gage outputs: (i) the iteration equation choice, (ii) the load format, (iii) the gage output format, and (iv) the combined influence of the non-linear terms of the regression model of the gage outputs. In addition, to complicate matters further, experience has shown that often the combination of these influence factors and not a single factor by itself determines if load iterations converge or diverge. Therefore, a systematic study was performed at the NASA Ames Balance Calibration Laboratory to better understand the connection between the different influence factors and the convergence behavior of the load iterations.

During the study it became clear that the four major influence factors can be reduced to two. This 
simplification is possible because the load and gage output formats are directly linked to the existence of the "primary gage sensitivities" of the balance data set. In addition, the role of influence factor (iv) can easily be understood as, by design, the load iteration scheme iterates in the neighborhood of a linear guess of the final solution. Therefore, it only works if the combined contribution of all non-linear terms of the regression model of the gage outputs is very small when compared with contributions from the linear terms.

In the next sections the remaining two influence factors, i.e., the iteration equation choice and the primary gage sensitivity, are discussed in more detail. Then, data from the calibration of a balance is used to illustrate the connection between the load iteration convergence and the two influence factors.

\section{Iteration Equation Choices}

The application of the Iterative Method in wind tunnel testing is supported by two load iteration equation choices. Either choice may be selected to predict wind tunnel balance loads from measured strain-gage outputs. Both iteration equation choices are constructed from the same global regression solution of the balance calibration data. Therefore, the two iteration equations will lead to the same predicted load values as long as the iterations themselves converge.

Unfortunately, the load iterations do not always converge. Detailed investigations at the Ames Balance Calibration Laboratory showed that situations exist when only one of the two iteration equations leads to convergence. These investigations confirmed that the difference in the convergence behavior is directly related to a limitation that is hidden in one of the two iteration equations. It is necessary to compare individual components of each iteration equation in more detail to better understand this limitation.

Table 1 below lists the two iteration equations that are used in the aerospace testing community. A detailed derivation of the iteration equation of the Primary Load Iteration Method, i.e., Eq. (1) in Table 1, may be found in Refs. [1] and [3]. The related derivation of the iteration equation used by the Alternate Load Iteration Method, i.e., Eq. (2) in Table 1, is given in Ref. [4]. For simplicity, the nomenclature introduced in Refs. [1], [3], and [4] in used in Table 1.

Both iteration equations, i.e., Eq. (1) and (2), share a common assumption: the linear terms of the regression model of the strain-gage outputs are by far the most dominant terms. This assumption can be quantified by computing the so-called percent contribution of each term of the regression model of the gage outputs (the calculation of the percent contribution is explained in detail in the appendix).

Table 1: Iteration equation choices of the Iterative Method.

\begin{tabular}{|c|c|}
\hline ITERATION METHOD & ITERATION EQUATION \\
\hline Primary Load Iteration Method & $\mathbf{F}_{\xi}=\underbrace{\left[\mathbf{C}_{\mathbf{1}}^{-1} \boldsymbol{\Delta}\right]}_{\text {constant }}-\underbrace{\left[\mathbf{C}_{\mathbf{1}}^{-1} \mathbf{C}_{\mathbf{2}}\right] \cdot \mathbf{H}_{\xi-1}}_{\text {changes for each iter. step }}$ \\
\hline Alternate Load Iteration Method & $\mathbf{F}_{\xi}=\underbrace{\left[\mathbf{B}_{\mathbf{1}}^{-1} \boldsymbol{\Delta} \mathbf{R}\right]}_{\text {constant }}-\underbrace{\left[\mathbf{B}_{1}^{-1} \mathbf{B}_{\mathbf{2}}\right] \cdot \mathbf{F}_{\xi-1}-\left[\mathbf{B}_{\mathbf{1}}^{-1} \mathbf{C}_{\mathbf{2}}\right] \cdot \mathbf{H}_{\xi-1}}_{\text {changes for each iteration step }}(2)$ \\
\hline
\end{tabular}

Comparing Eq. (1) with Eq. (2) it can be seen that each iteration equation has parts that depend on the load estimate of the previous iteration step and parts that are constant. Parts that depend on the load estimate of the previous iteration step are identified in Eqs. (1) and (2) by a subscript with the iteration step index $\xi$. The magnitude of these changing parts has to be significantly smaller than the magnitude of the constant parts for the iteration scheme to converge. Consequently, the convergence behavior of the load iteration process is directly connected with the magnitude of the constant part of the iteration equation.

Equations (1) and (2) in Table 1 show the constant part of each iteration equation choice. The constant part is also the first load estimate when the iteration process starts. The constant part of the first iteration equation equals the product of the inverse of matrix $\mathbf{C}_{\mathbf{1}}$ with the strain-gage output difference vector $\boldsymbol{\Delta} \mathbf{R}$. Similarly, the constant part of the second iteration equation equals the product of the inverse of matrix $\mathbf{B}_{\mathbf{1}}$ with the strain-gage output difference vector $\boldsymbol{\Delta} \mathbf{R}$. Square matrix $\mathbf{C}_{\mathbf{1}}$ and square matrix $\mathbf{B}_{\mathbf{1}}$ consist of parts of the regression coefficient matrix $\mathbf{C}$. Matrix $\mathbf{C}$ has the regression coefficients that are the result 
of the regression analysis of the balance calibration data. Matrix $\mathbf{C}_{\mathbf{1}}$ consists of all linear terms of the regression coefficient matrix $\mathbf{C}$. Matrix $\mathbf{B}_{\mathbf{1}}$, on the other hand, consists of only the linear terms on the principle diagonal of the regression coefficient matrix $\mathbf{C}$. All off-diagonal elements of matrix $\mathbf{B}_{\mathbf{1}}$ are zero. Therefore, the linear terms on the principle diagonal of the regression coefficient matrix $\mathbf{C}$ must be the dominant regression model terms in order for the second iteration equation choice, i.e., Eq. (2), to converge. Fortunately, the first iteration equation choice, i.e., Eq. (1), does not have this limitation.

Both the influence of terms on the principle diagonal of the matrix $\mathbf{B}_{\mathbf{1}}$ and the convergence behavior of iteration equation (2) can directly be related to the existence of the primary gage sensitivities. Therefore, a new definition for the existence of the primary gage sensitivity of a balance calibration data set is discussed in the next section. This definition may be used to investigate the convergence behavior of the load iterations.

\section{Primary Gage Sensitivities and Calibration Data Format}

Studies performed by the author showed that the chosen combination of the load and gage output format of the balance calibration data set has a direct influence on the convergence behavior of the load iteration equations that are listed in Table 1 . The selection essentially determines (i) which primary gage sensitivities of the balance gages exist and (ii) which iteration equation choice converges.

In principle, the primary sensitivity of a balance gage is defined as the partial derivative of a primary balance load with respect to the corresponding gage output. This definition assumes, of course, that the physical behavior of the balance is dominated by first order linear terms. Consequently, primary gage sensitivities can often be approximated by the coefficients on the principle diagonal of the data reduction matrix. We get, for example, the following set of sensitivities for a force balance calibration data set that is given in force balance format:

$$
\frac{\partial N 1}{\partial R 1}, \frac{\partial N 2}{\partial R 2}, \frac{\partial S 1}{\partial R 3}, \frac{\partial S 2}{\partial R 4}, \frac{\partial A F}{\partial R 5}, \frac{\partial R M}{\partial R 6}
$$

The iteration equations, as indicated in the previous section, will only converge if matrices $\mathbf{C}_{\mathbf{1}}$ and $\mathbf{B}_{\mathbf{1}}$ use the dominant coefficients that are contained in the regression coefficient matrix $\mathbf{C}$. The first (primary) iteration equation, i.e., Eq. (1), is structured such that this requirement is always fulfilled for a typical balance data set. Therefore, the first iteration equation and its convergence behavior are independent of the load and gage output format combination that is chosen for the calibration data analysis.

The situation is different for the second (alternate) load iteration equation, i.e., Eq. (2). It assumes that the dominant term of the regression coefficient matrix $\mathbf{C}$ is identical with the values on the principle diagonal of the linear part of the matrix. These values are the inverse of the primary gage sensitivities.

An important connection between the primary gage sensitivities and the load and gage output format combination of the calibration data exists that may be used to diagnose iteration convergence problems. This connection can be better understood if the different format choices are reviewed. Table 2 below shows typical load formats may be selected for the analysis of balance calibration data.

Table 2: Balance load formats.

\begin{tabular}{|c|c|}
\hline FORMAT NAME & LOAD COMPONENT LIST \\
\hline FORCE BALANCE FORMAT & $N 1, N 2, S 1, S 2, A F, R M$ \\
\hline MOMENT BALANCE FORMAT & $P M 1, P M 2, Y M 1, Y M 2, R M, A F$ \\
\hline DIRECT-READ FORMAT & $N F, S F, A F, P M, Y M, R M$ \\
\hline
\end{tabular}

The load formats can easily be transformed from one format to another by using load transformations that are listed in Ref. [6] for both a force and a moment balance.

Table 3 below shows different gage output formats that can be defined by using (i) the load transformation given in Ref. [6] and (ii) an assumed near-linear relationship between original loads and gage outputs. The transformed gage outputs neglect small differences that may exist between the constants of proportionality of related load and gage output sets.

American Institute of Aeronautics and Astronautics 
Table 3: Gage output formats.

\begin{tabular}{|c|c|}
\hline FORMAT NAME & GAGE OUTPUT LIST \\
\hline FORCE BALANCE FORMAT & $R 1, R 2, \cdots, R 6$ \\
\hline MOMENT BALANCE FORMAT & $\mathcal{R} 1, \mathcal{R} 2, \cdots, \mathcal{R} 6$ \\
\hline DIRECT-READ FORMAT (FORCE BAL.) & $R 1+R 2, R 1-R 2, R 3+R 4, R 3-R 4, R 5, R 6$ \\
\hline DIRECT-READ FORMAT (MOMENT BAL.) & $\mathcal{R} 2-\mathcal{R} 1, \mathcal{R} 1+\mathcal{R} 2, \mathcal{R} 4-\mathcal{R} 3, \mathcal{R} 3+\mathcal{R} 4, \mathcal{R} 5, \mathcal{R} 6$ \\
\hline
\end{tabular}

It is important to point out that the primary gage sensitivity of a balance gage only exists if the original (or transformed) gage output is directly proportional to the original (or transformed) balance load as the balance is traditionally assumed to be a first order linear device. For a force balance, for example, this means that the gage output $R 1$ of the forward normal force gage is proportional to the normal force component $N 1$ at the forward normal force gage. This condition, of course, is fulfilled whenever a force balance is analyzed in its "design" load format, i.e., in force balance format. The condition is also fulfilled if a moment balance is analyzed in moment balance format, or, a direct-read balance is analyzed in direct-read format.

The linear connection between load and gage output needs to be evaluated to determine if the related primary gage sensitivity exists. The following criterion is used at NASA Ames for that purpose:

\section{Empirical Criterion for the Non-Existence of the Primary Gage Sensitivity}

The primary sensitivity of a balance gage does not exist if one of two conditions is fulfilled: Condition 1 - The standard deviation of the linear fit of the gage outputs versus the corresponding primary gage load is greater than $5 \%$ of the gage output range. Condition $2-$ The difference between the linear estimate of the sensitivity and the value from the data reduction matrix is greater than $10 \%$.

Ultimately, all balance loads need to be transformed to the direct-read format so that aerodynamic loads on a wind tunnel model can correctly be interpreted. This transformation takes place either before or after the balance loads are processed using the Iterative Method. In most cases, the transformation is applied after the completion of the load iteration so that calibration data of a balance can be processed in its "design" format. Some balance users, however, prefer to apply the transformation of the balance loads from the "design" format to the direct-read format before the regression analysis of the balance calibration data takes place. Then, gage outputs of a force balance, for example, are fitted as a function of transformed loads in direct-read format. Consequently, four of the six gage outputs of a six-component balance are no longer proportional to the primary gage load. In other words - four of the six primary gage sensitivities no longer exist as a result of applying the load transformation to direct-read format before the regression analysis of the calibration data is performed. Therefore, the Iterative Method will no longer converge if the more limited second (alternate) iteration equation choice (Eq. (2)) is used. The first (primary) iteration equation choice (Eq. (1)), on the other hand, is independent of the load transformation to direct-read format and will still converge. The situation changes again if the gage outputs are also transformed to direct-read format as outlined in Table 3. Then, all primary gage sensitivities exist again and both load iteration equations converge. Table 4 below summarizes the connection between load and gage output format, primary gage sensitivity, iteration equation choice, and the convergence behavior of the Iterative Method for a force balance.

Table 4: Force Balance: Summary of load iteration convergence characteristics.

\begin{tabular}{|c|c|c|c|c|}
\hline $\begin{array}{c}\text { LOAD } \\
\text { FORMAT }\end{array}$ & $\begin{array}{c}\text { GAGE OUtPUt } \\
\text { FORMAT }\end{array}$ & $\begin{array}{c}\text { PRIMARY LOAD ITER. } \\
\text { METHOD CONVERGES ? } \\
\text { (METHOD USES EQ.(1)) }\end{array}$ & $\begin{array}{c}\text { ALTERNATE LOAD ITER. } \\
\text { METHOD CONVERGES ? } \\
\text { (METHOD USES EQ.(2)) }\end{array}$ & $\begin{array}{c}\text { ALL PRIM. } \\
\text { SENSITIV. } \\
\text { EXIST ? }\end{array}$ \\
\hline$N 1, N 2, \cdots$ & $R 1, R 2, \cdots$ & YES & YES & YES \\
$N F, P M, \cdots$ & $R 1, R 2, \cdots$ & YES & NO \\
$N F, P M, \cdots$ & $R 1+R 2, R 1-R 2, \cdots$ & YES & YES & YES \\
\hline
\end{tabular}

American Institute of Aeronautics and Astronautics 
Table 5 summarizes the connection between load and gage output format, primary gage sensitivity, iteration equation choice, and the convergence behavior of the Iterative Method for a moment balance.

Table 5: Moment Balance: Summary of load iteration convergence characteristics.

\begin{tabular}{|c|c|c|c|c|}
\hline $\begin{array}{c}\text { LOAD } \\
\text { FORMAT }\end{array}$ & $\begin{array}{c}\text { GAGE OUtPUt } \\
\text { FORMAt }\end{array}$ & $\begin{array}{c}\text { PRIMARY LOAD ITER. } \\
\text { METHOD CONVERGES ? } \\
\text { (METHOD USES EQ.(1)) }\end{array}$ & $\begin{array}{c}\text { ALtERnATE LOAD ITER. } \\
\text { METHOD CONVERGES ? } \\
\text { (METHOD USES EQ.(2)) }\end{array}$ & $\begin{array}{c}\text { ALL PRIM. } \\
\text { SENSITIV. } \\
\text { EXIST ? }\end{array}$ \\
\hline$P M 1, P M 2, \cdots$ & $\mathcal{R} 1, \mathcal{R} 2, \cdots$ & YES & YES & YES \\
$N F, P M, \cdots$ & $\mathcal{R} 1, \mathcal{R} 2, \cdots$ & YES & YES \\
$N F, P M, \cdots$ & $\mathcal{R} 2-\mathcal{R} 1, \mathcal{R} 1+\mathcal{R} 2, \cdots$ & YES & YES \\
\hline
\end{tabular}

A balance calibration data set example is discussed in the next section to illustrate the connection between the convergence of the Iterative Method and the existence of the primary gage sensitivities.

\section{Discussion of Example}

\section{A. General Remarks}

Data from the calibration of the NASA Ames MK40 balance was selected to illustrate the connection between the convergence behavior of the load iterations and the existence of the primary gage sensitivities. Figure 1 shows the MK40 balance. The MK40 is a six-component TASK balance that measures five forces and one moment $(N 1, N 2, S 1, S 2, A F, R M)$. It has a diameter of 2.5 inches and a total length of 17.31 inches. Table 6 shows the load capacity of each load component.

Table 6: Load capacities of the NASA Ames 2.5in MK40 balance.

\begin{tabular}{|l|c|c|c|c|c|c|}
\hline & $N 1, \mathrm{lbs}$ & $N 2, \mathrm{lbs}$ & $S 1, \mathrm{lbs}$ & $S 2, \mathrm{lbs}$ & $A F, \mathrm{lbs}$ & $R M$, in-lbs \\
\hline CAPACITY & 3500 & 3500 & 2500 & 2500 & 400 & 8000 \\
\hline
\end{tabular}

The calibration of the balance was performed using the "hand load" method. A total of 164 data points were taken in 16 load series. The balance loads were corrected for the weight of the balance shell, calibration body, and other hardware before the regression analysis started so that a common calibration data set could be used for the current investigations. Then, the tare corrected calibration data was analyzed using the different load and gage output format combinations that were listed in Table 2 and Table 3. A quadratic plus a simple absolute value term was chosen as the regression model for all data sets that were analyzed.

\section{B. Analysis Results for Loads and Outputs in Original Format}

In a first step the calibration data was processed in the original load and gage output format. Figure 2 shows the strain-gage outputs $R 1$ and $R 2$ plotted versus the corresponding loads $N 1$ and $N 2$. In this case the linear connection between load and gage output is immediately apparent. Figure 3a shows the fitted regression coefficients of the six gage outputs. Figure 3b shows the corresponding percent contributions. It can clearly be seen that the six terms on the principle diagonal of the matrix dominate the regression model (they have a percent contribution of $100 \%$ ).

Figure 4a shows the data reduction matrix that was derived for the Primary Load Iteration Method from the regression coefficient matrix shown in Fig. 3a. Figure $4 \mathrm{~b}$ shows the result of the load iteration process. As expected, the iterations show excellent convergence.

Figure 5a shows the data reduction matrix that was derived for the Alternate Load Iteration Method from the regression coefficient matrix shown in Fig. 3a. Figure 5b shows the result of the load iteration process. Again, as all primary gage sensitivities exist, the iterations show excellent convergence.

\section{Analysis Results for Loads in Direct-Read Format}

In the next part of the study the original balance loads were transformed from force balance to directread format. The load transformation was performed by using the following relationships (from Ref. [6]): 


$\begin{aligned} N F & =N 1+N 2 \\ P M & =[N 1-N 2] \cdot p / 2 \\ S F & =S 1+S 2 \\ Y M & =[S 1-S 2] \cdot q / 2 \\ A F \& R M & \Longrightarrow \text { not transformed }\end{aligned}$

The gage outputs remained unchanged. Figure 6a shows the original outputs $R 1$ and $R 2$ plotted versus the transformed loads $N F$ and $P M$. In this case the linear connection between load and gage output no longer exists. Therefore, the primary gage sensitivities of the two gages can no longer be defined. The same observation was made when the outputs $R 3$ and $R 4$ were plotted versus the transformed loads $S F$ and $Y M$. The remaining two load components, i.e., $A F$ and $R M$, were not transformed and still show a clear linear relationship to the corresponding gage outputs (see Fig. 6b).

Figure 7a shows the fitted regression coefficients of the six gage outputs. Figure $7 \mathrm{~b}$ shows the corresponding percent contributions. It can be seen that four of the six fitted gage outputs no longer have a single dominating term on the principle diagonal. Gage output $R 1$, for example, has a percent contribution of $100.00 \%$ for $N F$ and a percent contribution of $52.38 \%$ for PM.

Figure 8a shows the result of the load iteration process for the Primary Load Iteration Method. As expected, the iterations show excellent convergence because the convergence of the Primary Load Iteration Method is independent of the existence of the primary gage sensitivities. Figure 8b shows the result of the load iteration process for the Alternate Load Iteration Method. This time the iterations diverge because the convergence of the Alternate Load Iteration Method requires the existence of all primary gage sensitivities.

\section{Analysis Results for Loads and Gage Outputs in Direct-Read Format}

In the last part of the study both the original balance loads and the original gage outputs were transformed from force balance format to direct-read format. The load transformation are listed above. The corresponding gage output transformations to direct-read format can be summarized as follows:

\begin{tabular}{rlr|}
$R 1^{\prime}$ & $=R 1+R 2$ & $(4 a)$ \\
$R 2^{\prime}$ & $=R 1-R 2$ & $(4 b)$ \\
$R 3^{\prime}$ & $=R 3+R 4$ & $(4 c)$ \\
$R 4^{\prime}$ & $=R 3-R 4$ & $(4 d)$ \\
$R 5 \& R 6$ & $\Longrightarrow$ not transformed & $(4 e)$
\end{tabular}

Figure 9a shows the transformed outputs $R 1^{\prime}$ and $R 2^{\prime}$ plotted versus the transformed loads $N F$ and $P M$. Now, the linear connection between load and gage output exists and the primary gage sensitivities of the two gages can be defined. The same observation was made when outputs $R 3^{\prime}$ and $R 4^{\prime}$ were plotted versus the transformed loads $S F$ and $Y M$.

Figure $9 \mathrm{~b}$ shows the percent contribution of the fitted regression coefficients of the six gage outputs. It can be seen that all six fitted gage outputs have a single dominating term each on the principle diagonal. All off-diagonal terms have a significantly smaller influence on the fitted gage outputs.

Figure 10a shows the result of the load iteration process for the Primary Load Iteration Method. Fig- 
ure 10b shows the result of the load iteration process for the Alternate Load Iteration Method. As expected, both iteration methods show excellent convergence because all primary gage sensitivities of the balance exist in the chosen load and gage output format.

\section{Summary and Conclusions}

The connection between the existence of the primary gage sensitivities and the convergence of the iteration equation choices used by the Iterative Method was investigated. First, basic elements of the two iteration equation choices, i.e., Eqs. (1) and (2), were reviewed. Then, an "empirical" criterion was presented that may be used to determine wheather or not the primary gage sensitivities of a balance calibration data set exist. Finally, the convergence characteristics of the two iteration equation choices were compared for different combinations of load and gage output formats. Data from the calibration of a force balance was used to demonstrate important connections between the format combinations and the convergence characteristics.

The study illustrated that both load iteration equations converge for typical balance calibration data sets as long as (i) all primary gage sensitivities exist, (ii) a good regression model is used for the analysis of the gage outputs, and (iii) the combined influence all non-linear terms is small when compared with the linear terms. It was also shown that the iteration equation of the Primary Load Iteration Method, i.e., Eq. (1), is more widely applicable and less restricted than the iteration equation of the Alternate Load Iteration Method, i.e., Eq. (2). Only the iteration equation of the Primary Load Iteration Method, for example, will converge if not all primary gage sensitivities of a data set exist. This situation typically occurs whenever a force or moment balance calibration data set is analyzed in direct-read format using the original gage outputs.

\section{Acknowledgements}

The author would like to thank Tom Volden of Jacobs Technology for his critical and constructive review of the final manuscript. The work reported in this paper was supported by the Wind Tunnel Division at NASA Ames Research Center under contract NNA09DB39C.

\section{References}

${ }^{1}$ AIAA/GTTC Internal Balance Technology Working Group, "Recommended Practice, Calibration and Use of Internal Strain-Gage Balances with Application to Wind Tunnel Testing," AIAA R-091-2003, American Institute of Aeronautics and Astronautics, Reston, Virginia, 2003, pp. 7-19.

${ }^{2}$ Ulbrich, N., "Comparison of Iterative and Non-Iterative Strain-Gage Balance Load Calculation Methods," AIAA 2010-4202, paper presented at the 27th AIAA Aerodynamic Measurement Technology and Ground Testing Conference, Chicago, Illinois, June/July 2010.

${ }^{3}$ Ulbrich, N. and Volden, T., "Strain-Gage Balance Calibration Analysis Using Automatically Selected Math Models," AIAA 2005-4084, paper presented at the 41st AIAA/ASME/SAE/ASEE Joint Propulsion Conference and Exhibit, Tucson, Arizona, July 2005, pp. 9-13.

${ }^{4}$ Ulbrich, N. and Volden, T., "Application of a New Calibration Analysis Process to the MK-III-C Balance," AIAA 2006-0517, paper presented at the 44th AIAA Aerospace Sciences Meeting and Exhibit, Reno, Nevada, January 2006, pp. 9-12.

${ }^{5}$ Ulbrich, N. and Volden, T., "Regression Analysis of Experimental Data Using an Improved Math Model Search Algorithm," AIAA 2008-0833, paper presented at the 46th AIAA Aerospace Sciences Meeting and Exhibit, Reno, Nevada, January 2008, p. 4, 4th paragraph.

${ }^{6}$ Ulbrich, N. and Bader, J., "Analysis of Sting Balance Calibration Data Using Optimized Regression Models," AIAA 2009-5372, paper presented at the 45th AIAA/ASME/SAE/ASEE Joint Propulsion Conference and Exhibit, Denver, Colorado, August 2009, pp. 18-21. 


\section{Appendix - Definition of the Percent Contribution}

The percent contribution describes the contribution of each term of the regression model of the gage outputs to the total fitted value, expressed as a percentage of the contribution of the principle diagonal term. It is used to assess the degree of linearity of the regression model of the gage outputs. In addition, some analysts use the "empirical" percent contribution threshold of $0.05 \%$ to identify terms in the model that make a very small contribution to the fitted gage outputs.

The percent contribution is defined as the ratio of two numerical values. This ratio is expressed as a percentage. The percent contribution only depends on (i) the known capacities of the load components of the balance and (ii) the regression coefficients that are the result of the regression analysis of the balance calibration data. For convenience, the regression coefficient nomenclature introduced in Ref. [1], Eq. (3.1.3), may be used to illustrate the calculation of the percent contribution. Then, the first numerical value can be expressed as the product of the regression coefficient of the primary linear term " $b 1(i, i)$ " of the regression model of the gage output with the capacity " $K(i)$ " of the related balance load component. We get:

$$
Q(i)=b 1(i, i) \cdot K(i)
$$

Equation (5) defines the reference value that is used to investigate the linearity of the regression model of the gage output. It is the denominator of the ratio that defines the percent contribution. The numerator of the ratio, on the other hand, is the product of the investigated regression coefficient with the related regressor variable value that is obtained by using the load capacities as applied loads. Now, the percent contribution of the ten math term type groups defined in Ref. [1], Eq. (3.1.3), can be summarized as follows:

$$
\begin{aligned}
& P(i, b 1)=100 \% \cdot[b 1(i, j) \cdot K(j)] / Q(i) \\
& P(i, b 2)=100 \% \cdot[b 2(i, j) \cdot|K(j)|] / Q(i) \\
& P(i, c 1)=100 \% \cdot\left[c 1(i, j) \cdot K(j)^{2}\right] / Q(i) \\
& P(i, c 2)=100 \% \cdot[c 2(i, j) \cdot K(j) \cdot|K(j)|] / Q(i) \\
& P(i, c 3)=100 \% \cdot[c 3(i, j, k) \cdot K(j) \cdot K(k)] / Q(i) \\
& P(i, c 4)=100 \% \cdot[c 4(i, j, k) \cdot|K(j) \cdot K(k)|] / Q(i) \\
& P(i, c 5)=100 \% \cdot[c 5(i, j, k) \cdot K(j) \cdot|K(k)|] / Q(i) \\
& P(i, c 6)=100 \% \cdot[c 6(i, j, k) \cdot|K(j)| \cdot K(k)] / Q(i) \\
& P(i, d 1)=100 \% \cdot\left[d 1(i, j) \cdot K(j)^{3}\right] / Q(i) \\
& P(i, d 2)=100 \% \cdot\left[d 2(i, j) \cdot\left|K(j)^{3}\right|\right] / Q(i)
\end{aligned}
$$

where $j=1, \cdots, n$ and $k=j+1, \cdots, n$. The numerator of the percent contribution, i.e., $Q(i)$, depends on the gage output index $i$. It changes whenever the index of the gage output changes during the calculation of the percent contribution. 


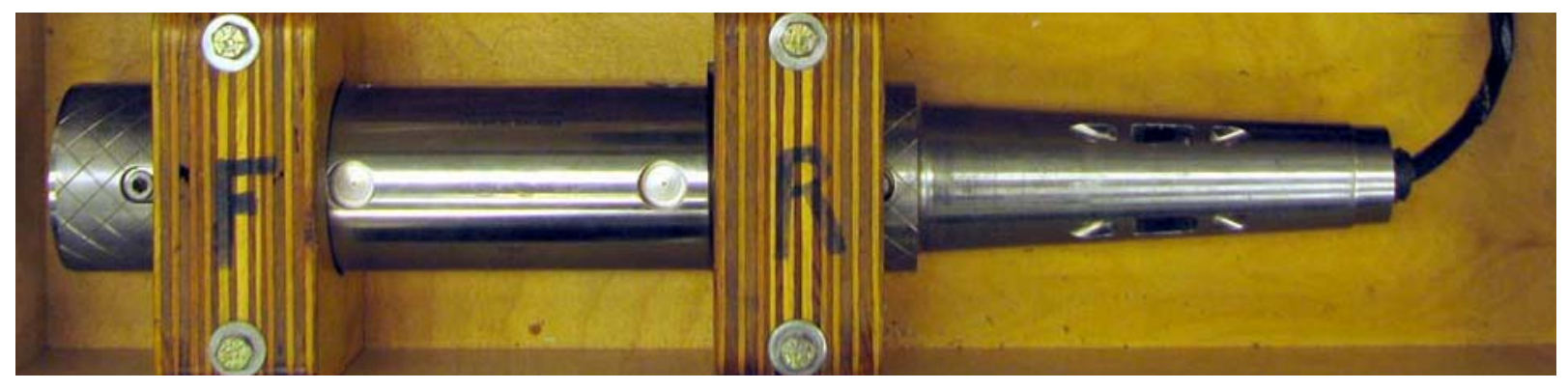

Fig. 1 NASA Ames 2.5in MK40 Task Balance.

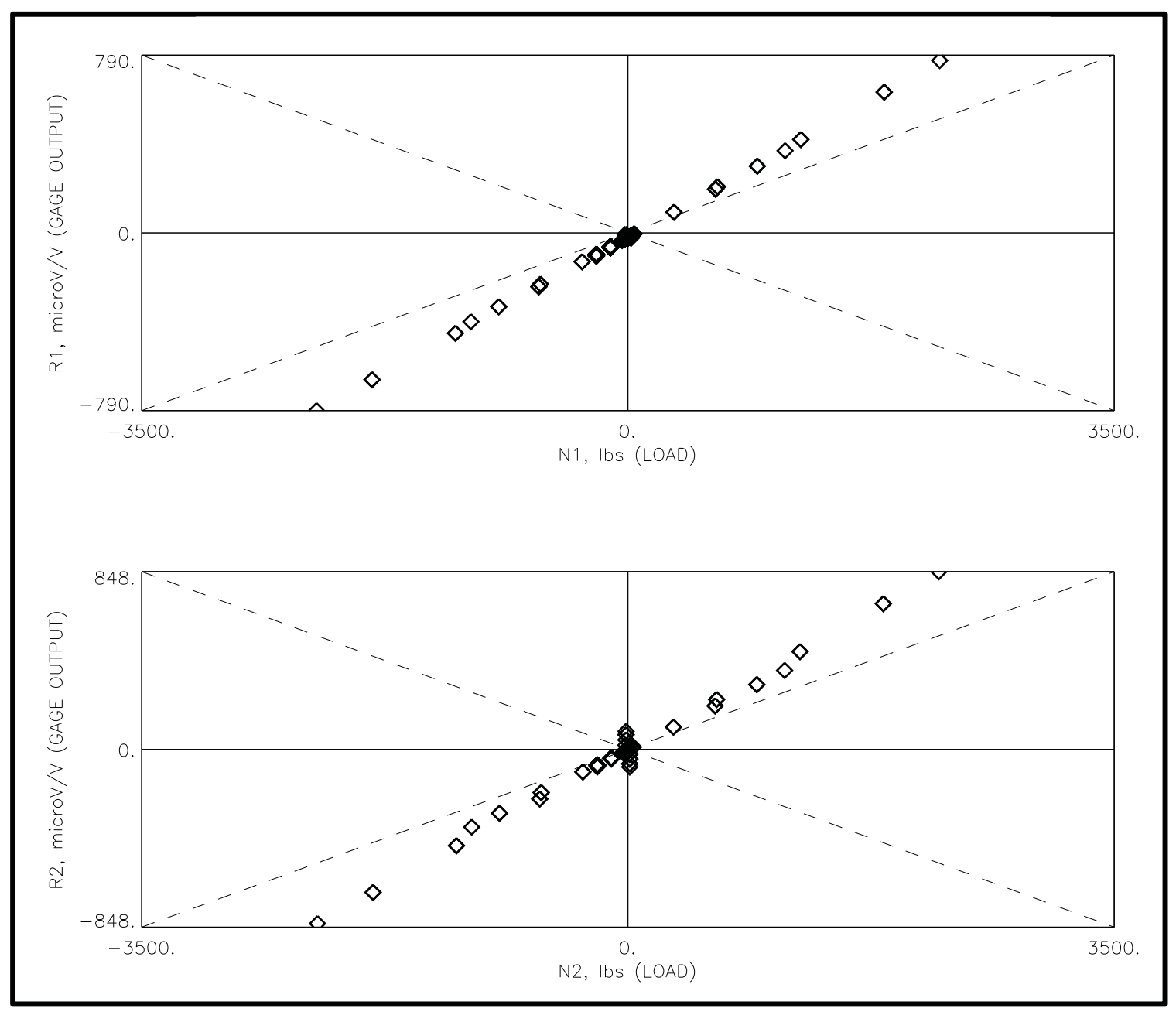

Fig. 2 Force Balance Format: Original gage outputs $R 1 \& R 2$ versus original loads $N 1 \& N 2$. 


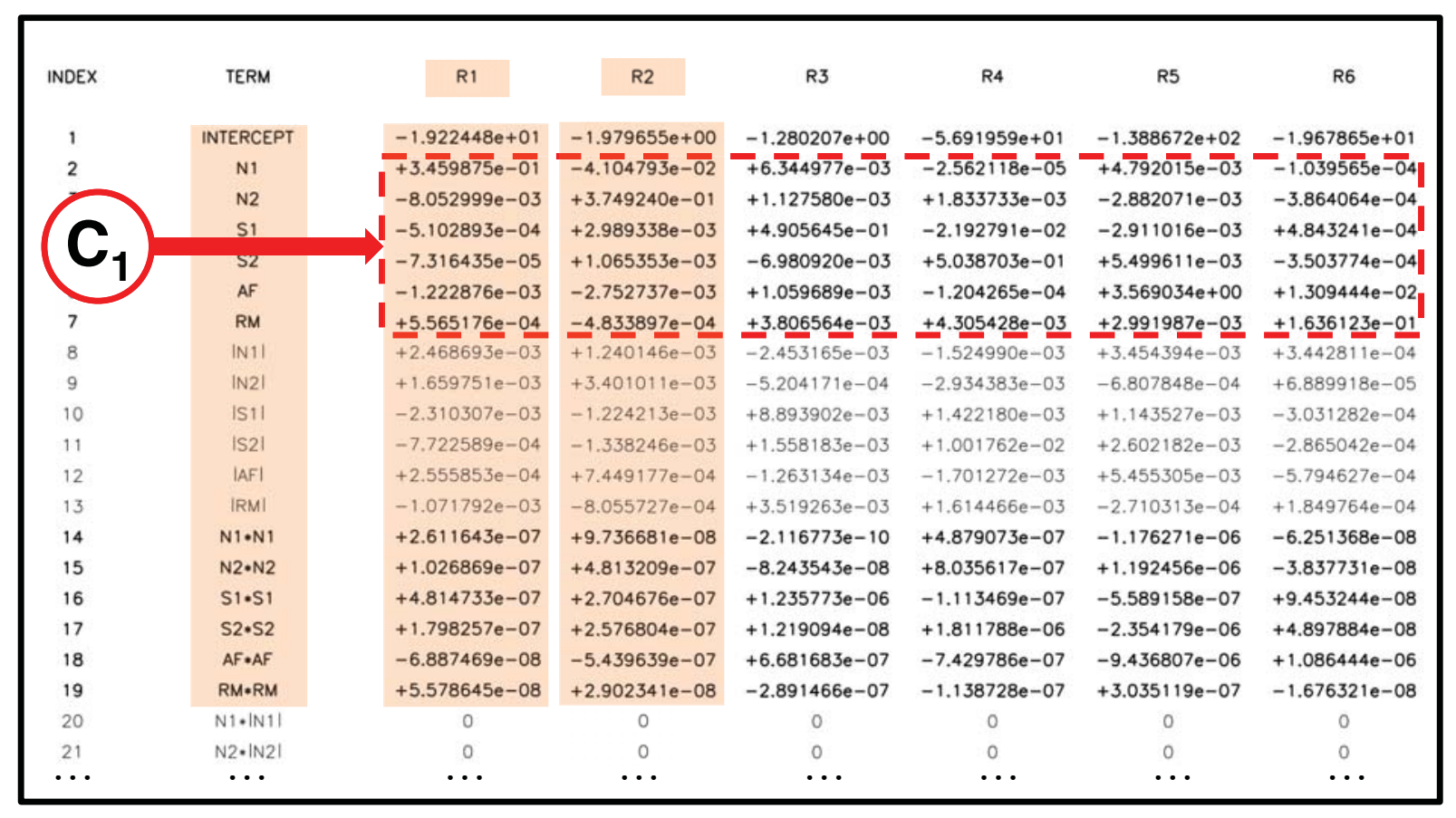

Fig. 3a Force Balance Format: Regression coefficient matrix of gage outputs $R 1$ to $R 6$.

\begin{tabular}{|c|c|c|c|c|c|c|c|}
\hline INDEX & TERM & R1 & R2 & R3 & R4 & R5 & R6 \\
\hline 1 & INTERCEPT & $-1.59 \%$ & $-0.15 \%$ & $-0.10 \%$ & $-4.52 \%$ & $-9.73 \%$ & $-1.50 \%$ \\
\hline 2 & N1 & $+100.00 \%$ & $-10.95 \%$ & $+1.81 \%$ & $-0.01 \%$ & $+1.17 \%$ & $-0.03 \%$ \\
\hline 3 & N2 & $-2.33 \%$ & $+100.00 \%$ & $+0.32 \%$ & $+0.51 \%$ & $-0.71 \%$ & $-0.10 \%$ \\
\hline 4 & si & $-0.11 \%$ & $+0.57 \%$ & $+100.00 \%$ & $-4.35 \%$ & $-0.51 \%$ & $+0.09 \%$ \\
\hline 5 & S2 & $-0.02 \%$ & $+0.20 \%$ & $-1.42 \%$ & $+100.00 \%$ & $+0.96 \%$ & $-0.07 \%$ \\
\hline 6 & $\mathrm{AF}$ & $-0.04 \%$ & $-0.08 \%$ & $+0.03 \%$ & $-3.82 e-03 \%$ & $+100.00 \%$ & $+0.40 \%$ \\
\hline 7 & RM & $+0.37 \%$ & $-0.29 \%$ & $+2.48 \%$ & $+2.73 \%$ & $+1.68 \%$ & $+100.00 \%$ \\
\hline 8 & IN1I & $+0.71 \%$ & $+0.33 \%$ & $-0.70 \%$ & $-0.42 \%$ & $+0.85 \%$ & $+0.09 \%$ \\
\hline 9 & IN2| & $+0.48 \%$ & $+0.91 \%$ & $-0.15 \%$ & $-0.82 \%$ & $-0.17 \%$ & $+0.02 \%$ \\
\hline 10 & $|s 1|$ & $-0.48 \%$ & $-0.23 \%$ & $+1.81 \%$ & $+0.28 \%$ & $+0.20 \%$ & $-0.06 \%$ \\
\hline 11 & $|\mathrm{~S} 2|$ & $-0.16 \%$ & $-0.25 \%$ & $+0.32 \%$ & $+1.99 \%$ & $+0.46 \%$ & $-0.05 \%$ \\
\hline 12 & |AFI & $+0.01 \%$ & $+0.02 \%$ & $-0.04 \%$ & $-0.05 \%$ & $+0.15 \%$ & $-0.02 \%$ \\
\hline 13 & |RMI & $-0.71 \%$ & $-0.49 \%$ & $+2.30 \%$ & $+1.03 \%$ & $-0.15 \%$ & $+0.11 \%$ \\
\hline 14 & $\mathrm{~N} 1 \cdot \mathrm{N} 1$ & $+0.26 \%$ & $+0.09 \%$ & $-2.11 e-04 \%$ & $+0.47 \%$ & $-1.01 \%$ & $-0.06 \%$ \\
\hline 15 & $\mathrm{~N} 2 \bullet \mathrm{N} 2$ & $+0.10 \%$ & $+0.45 \%$ & $-0.08 \%$ & $+0.78 \%$ & $+1.02 \%$ & $-0.04 \%$ \\
\hline 16 & $\mathrm{~S} 1 \cdot \mathrm{S} 1$ & $+0.25 \%$ & $+0.13 \%$ & $+0.63 \%$ & $-0.06 \%$ & $-0.24 \%$ & $+0.05 \%$ \\
\hline 17 & $\mathrm{~S} 2 \cdot \mathrm{s} 2$ & $+0.09 \%$ & $+0.12 \%$ & $+0.01 \%$ & $+0.90 \%$ & $-1.03 \%$ & $+0.02 \%$ \\
\hline 18 & $A F \cdot A F$ & $-9.10 e-04 \%$ & $-0.01 \%$ & $+0.01 \%$ & $-0.01 \%$ & $-0.11 \%$ & $+0.01 \%$ \\
\hline 19 & $R M \cdot R M$ & $+0.29 \%$ & $+0.14 \%$ & $-1.51 \%$ & $-0.58 \%$ & $+1.36 \%$ & $-0.08 \%$ \\
\hline 20 & $\mathrm{~N} 1 \cdot|\mathrm{N} 1|$ & 0 & 0 & 0 & 0 & 0 & 0 \\
\hline 21 & $\mathrm{~N} 2 \cdot|\mathrm{N} 2|$ & 0 & 0 & 0 & 0 & 0 & 0 \\
\hline$\cdots$ & $\ldots$ & $\cdots$ & $\cdots$ & $\cdots$ & $\cdots$ & $\cdots$ & $\cdots$ \\
\hline
\end{tabular}

Fig. 3b Force Balance Format: Percent contribution of regression coefficients of gage outputs.

American Institute of Aeronautics and Astronautics 


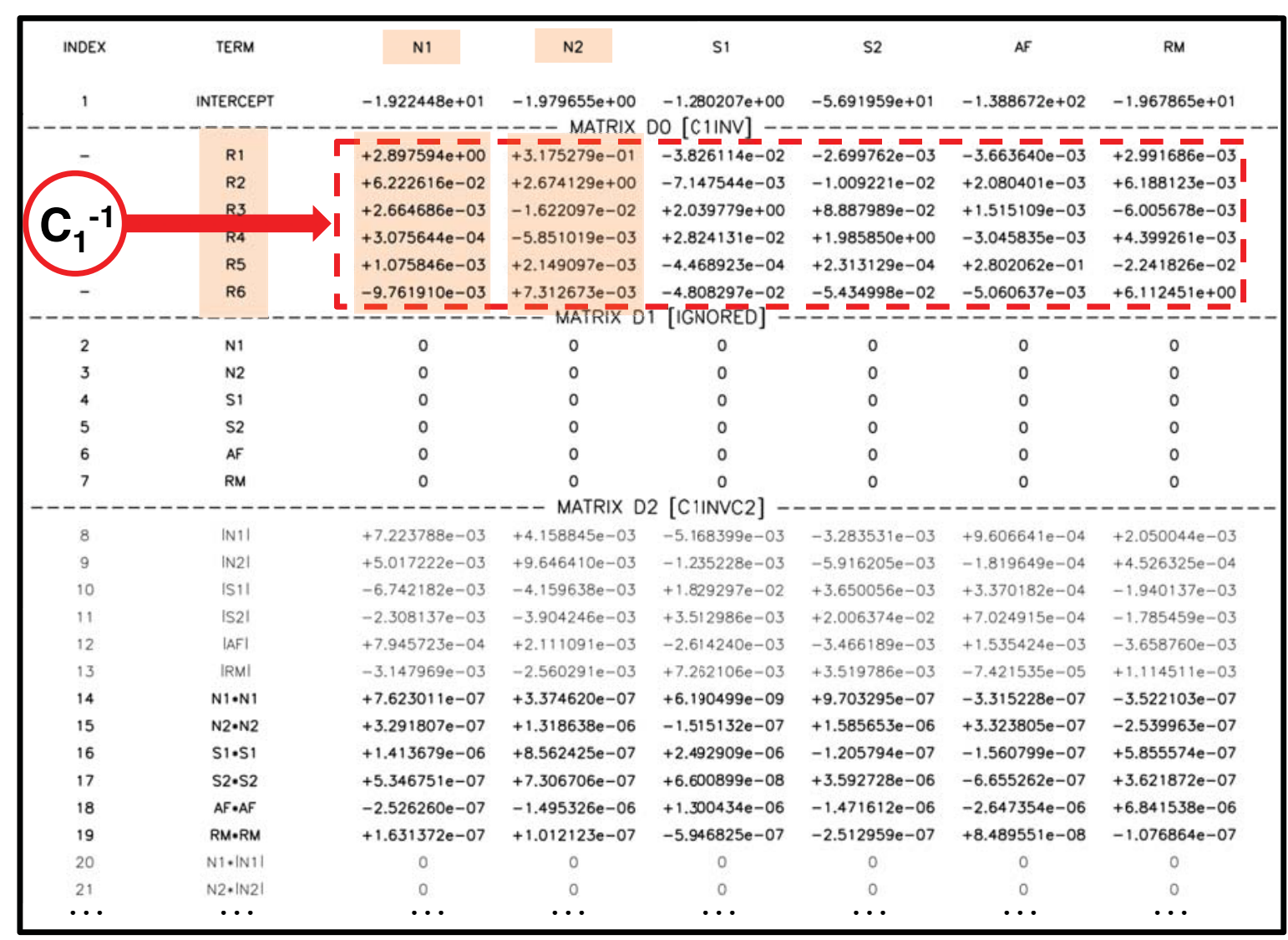

Fig. 4a Force Balance Format: Data reduction matrix for Primary Load Iteration Method.

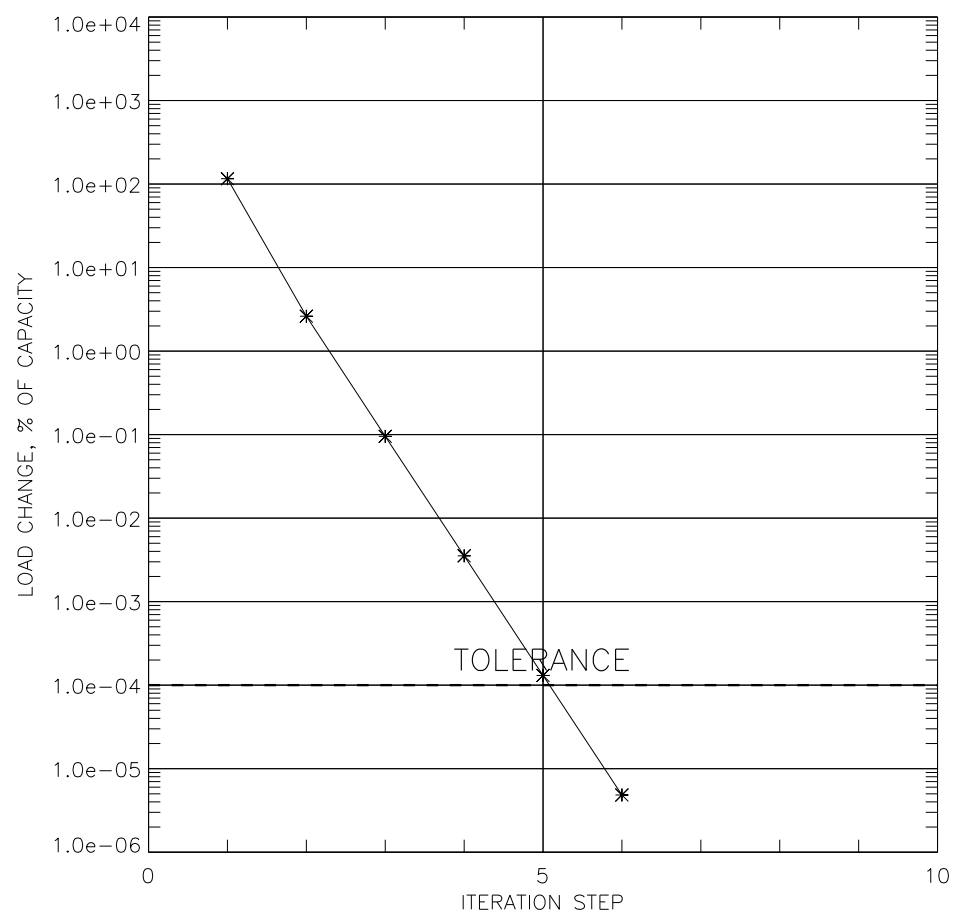

Fig. 4b Force Balance Format: Iteration result for Primary Load Iteration Method (Eq. (1)).

American Institute of Aeronautics and Astronautics 


\begin{tabular}{|c|c|c|c|c|c|c|c|}
\hline INDEX & TERM & N1 & N2 & S1 & \$2 & AF & $\mathrm{RM}$ \\
\hline 1 & INTERCEPT & $-1.922448 \mathrm{e}+01$ & $-1.979655 e+00$ & $-1.280207 e+00$ & $-5.691959 e+01$ & $-1.388672 \mathrm{e}+02$ & $-1.967865 e+01$ \\
\hline - & R1 & $+2.890278 \mathrm{e}+00$ & $=\int_{0}^{\text {MATRIX }}$ & $\underset{0}{[\mathrm{~B} 1 \mathrm{INV}]}-$ & $=\frac{---}{0}$ & $=--$ & -- \\
\hline & R2 & 0 & $+2.667207 e+00$ & 0 & 0 & 0 & 0 \\
\hline & R3 & 0 & 0 & $+2.038468 \mathrm{e}+00$ & 0 & 0 & 0 \\
\hline & R4 & 0 & 0 & 0 & $+1.984638 \mathrm{e}+00$ & 0 & 0 \\
\hline & R5 & 0 & 0 & 0 & 0 & $+2.801879 \mathrm{e}-01$ & 0 \\
\hline - & R6 & 0 & -0 & ${ }^{0}$ & $--^{0}-$ & $-0=$ & $+6.112009 \mathrm{e}+00$ \\
\hline 2 & N1 & 0 & $-1.094833 e-01$ & $+1.293403 e-02$ & $-5.084875 e-05$ & $+1.342664 e-03$ & $-6.353832 \mathrm{e}-04$ \\
\hline 3 & N2 & $-2.327541 e-02$ & 0 & $+2.298536 \mathrm{e}-03$ & $+3.639295 e-03$ & $-8.075214 e-04$ & $-2.361719 \mathrm{e}-03$ \\
\hline 4 & s1 & $-1.474878 \mathrm{e}-03$ & $+7.973184 \mathrm{e}-03$ & 0 & $-4.351895 e-02$ & $-8.156314 e-04$ & $+2.960193 \mathrm{e}-03$ \\
\hline 5 & s2 & $-2.114653 e-04$ & $+2.841518 \mathrm{e}-03$ & $-1.423038 \mathrm{e}-02$ & 0 & $+1.540924 \mathrm{e}-03$ & $-2.141509 \mathrm{e}-03$ \\
\hline 6 & Af & $-3.534453 e-03$ & $-7.342119 \mathrm{e}-03$ & $+2.160141 \mathrm{e}-03$ & $-2.390029 \mathrm{e}-04$ & 0 & $+8.003331 \mathrm{e}-02$ \\
\hline 7 & RM & $+1.608491 \mathrm{e}-03$ & $-1.289300 \mathrm{e}-03$ & $+7.759560 \mathrm{e}-03$ & $+8.544714 \mathrm{e}-03$ & $+8.383184 \mathrm{e}-04$ & 0 \\
\hline & --- & --------- & --- MATRIX D & [B1INVC2] - & ------- & --------1 & --------- \\
\hline 8 & IN1I & $+7.135209 \mathrm{e}-03$ & $+3.307725 e-03$ & $-5.000699 e-03$ & $-3.026552 e-03$ & $+9.678793 e-04$ & $+2.104249 e-03$ \\
\hline 9 & IN2| & $+4.797142 e-03$ & $+9.071201 \mathrm{e}-03$ & $-1.060854 \mathrm{e}-03$ & $-5.823687 e-03$ & $-1.907476 \mathrm{e}-04$ & $+4.211124 \mathrm{e}-04$ \\
\hline 10 & $|s| 1$ & $-6.677428 \mathrm{e}-03$ & $-3.265229 \mathrm{e}-03$ & $+1.812993 \mathrm{e}-02$ & $+2.822512 \mathrm{e}-03$ & $+3.204024 \mathrm{e}-04$ & $-1.852722 \mathrm{e}-03$ \\
\hline 11 & |S21 & $-2.232043 e-03$ & $-3.569378 e-03$ & $+3.176307 \mathrm{e}-03$ & $+1.988134 \mathrm{e}-02$ & $+7.290998 \mathrm{e}-04$ & $-1.751116 \mathrm{e}-03$ \\
\hline 12 & $|A F|$ & $+7.387125 e-04$ & $+1.986850 \mathrm{e}-03$ & $-2.574859 e-03$ & $-3.376408 e-03$ & $+1.528510 \mathrm{e}-03$ & $-3.541681 \mathrm{e}-03$ \\
\hline 13 & |RMI & $-3.097777 e-03$ & $-2.148629 e-03$ & $+7.173905 \mathrm{e}-03$ & $+3.204130 \mathrm{e}-03$ & $-7.593969 \mathrm{e}-05$ & $+1.130577 \mathrm{e}-03$ \\
\hline 14 & $\mathrm{~N} 1 \cdot \mathrm{N} 1$ & $+7.548375 e-07$ & $+2.596974 \mathrm{e}-07$ & $-4.314974 e-10$ & $+9.683191 \mathrm{e}-07$ & $-3.295769 \mathrm{e}-07$ & $-3.820841 \mathrm{e}-07$ \\
\hline 15 & $\mathrm{~N} 2 \cdot \mathrm{N} 2$ & $+2.967937 \mathrm{e}-07$ & $+1.283783 \mathrm{e}-06$ & $-1.680420 e-07$ & $+1.594779 \mathrm{e}-06$ & $+3.341116 \mathrm{e}-07$ & $-2.345624 e-07$ \\
\hline 16 & $\mathrm{~S} 1 \cdot \mathrm{S} 1$ & $+1.391592 \mathrm{e}-06$ & $+7.213930 \mathrm{e}-07$ & $+2.519084 \mathrm{e}-06$ & $-2.209832 e-07$ & $-1.566014 \mathrm{e}-07$ & $+5.777831 \mathrm{e}-07$ \\
\hline 17 & $\mathrm{~S} 2 \cdot \mathrm{S} 2$ & $+5.197462 \mathrm{e}-07$ & $+6.872871 e-07$ & $+2.485085 \mathrm{e}-08$ & $+3.595742 \mathrm{e}-06$ & $-6.596125 e-07$ & $+2.993591 \mathrm{e}-07$ \\
\hline 18 & $A F \bullet A F$ & $-1.990670 e-07$ & $-1.450864 e-06$ & $+1.362040 \mathrm{e}-06$ & $-1.474543 e-06$ & $-2.644079 e-06$ & $+6.640354 e-06$ \\
\hline 19 & $R M \bullet R M$ & $+1.612384 \mathrm{e}-07$ & $+7.741145 e-08$ & $-5.894161 e-07$ & $-2.259963 e-07$ & $+8.504036 \mathrm{e}-08$ & $-1.024569 e-07$ \\
\hline 20 & $\mathrm{~N} 1 \cdot|\mathrm{N} 1|$ & 0 & 0 & 0 & 0 & 0 & 0 \\
\hline 21 & $\mathrm{~N} 2 \cdot|\mathrm{N} 2|$ & 0 & 0 & 0 & 0 & 0 & 0 \\
\hline$\cdots$ & $\cdots$ & $\cdots$ & $\cdots$ & $\cdots$ & $\cdots$ & $\cdots$ & $\cdots$ \\
\hline
\end{tabular}

Fig. 5a Force Balance Format: Data reduction matrix for Alternate Load Iteration Method.

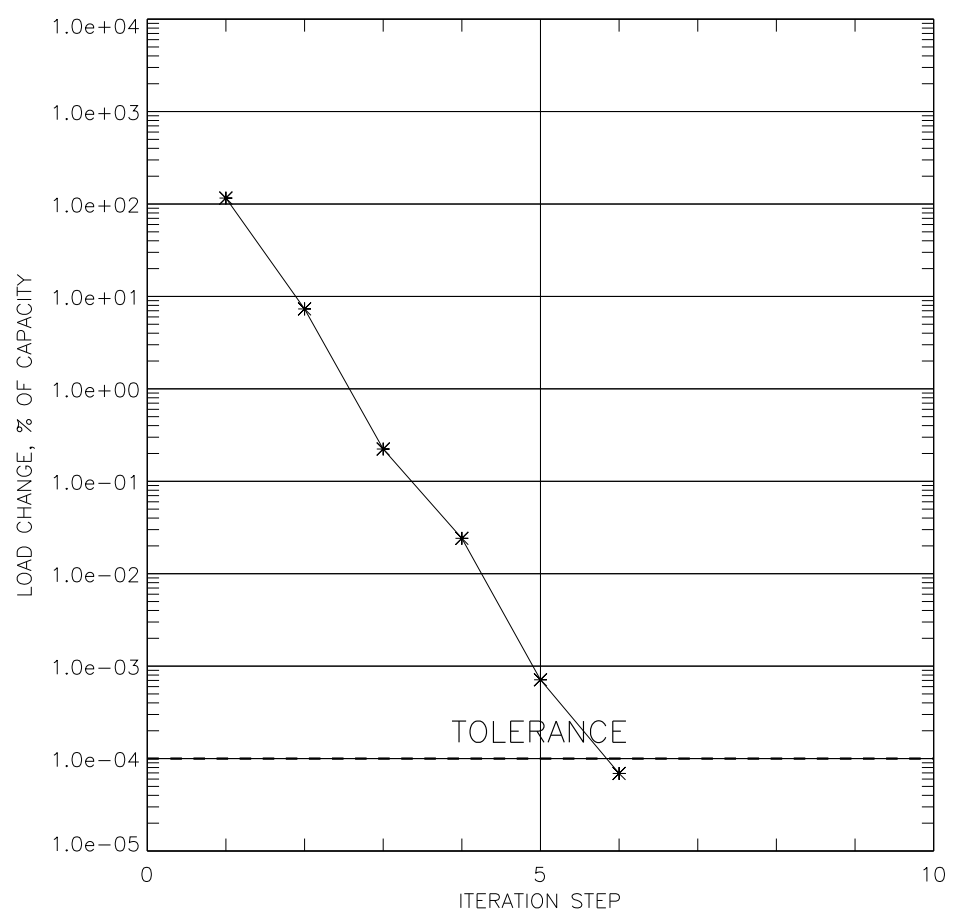

Fig. 5b Force Balance Format: Iteration result for Alternate Load Iteration Method (Eq. (2)).

American Institute of Aeronautics and Astronautics 


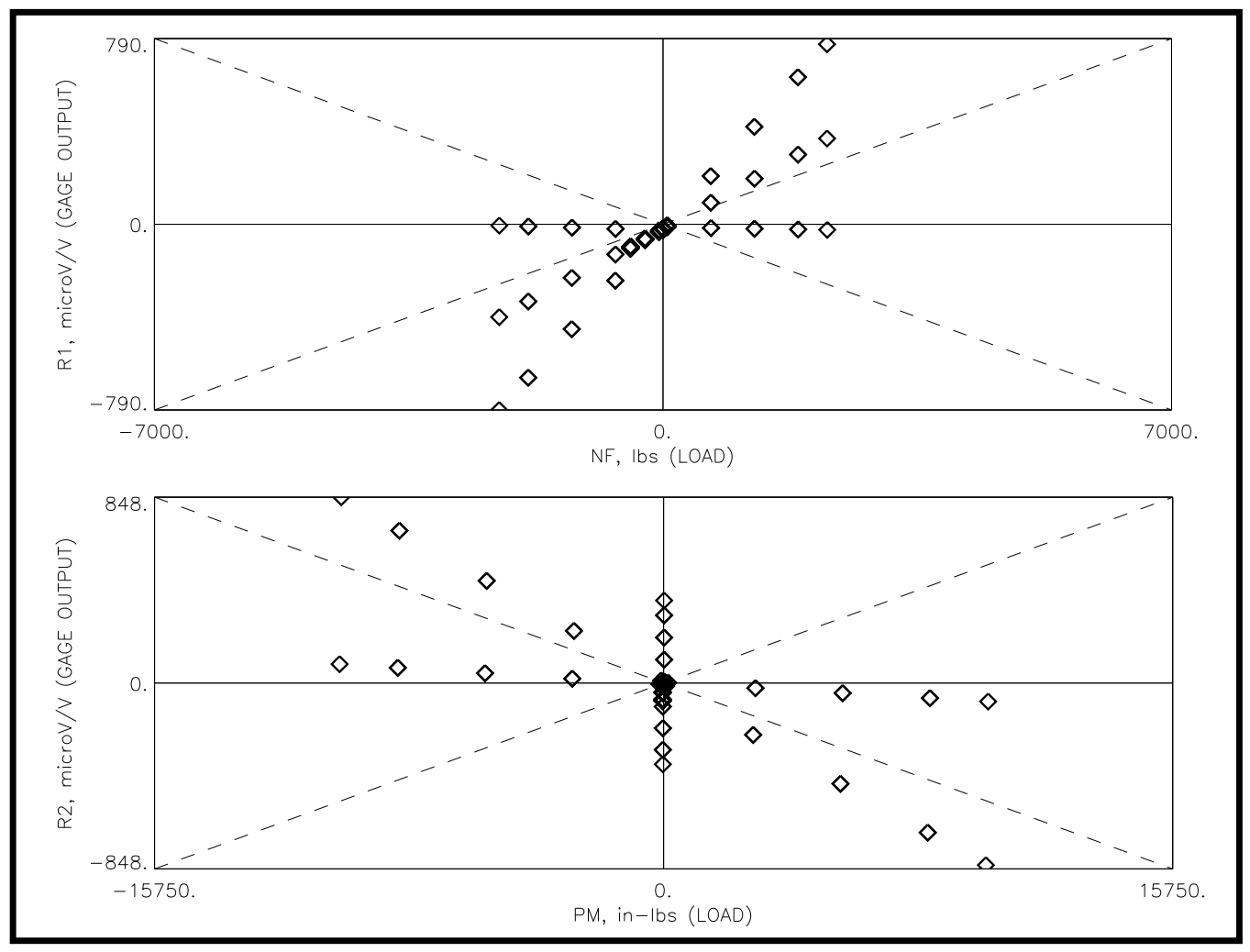

Fig. 6a Direct-Read Format: Original gage outputs $R 1 \& R 2$ versus transformed loads $N F \& P M$.

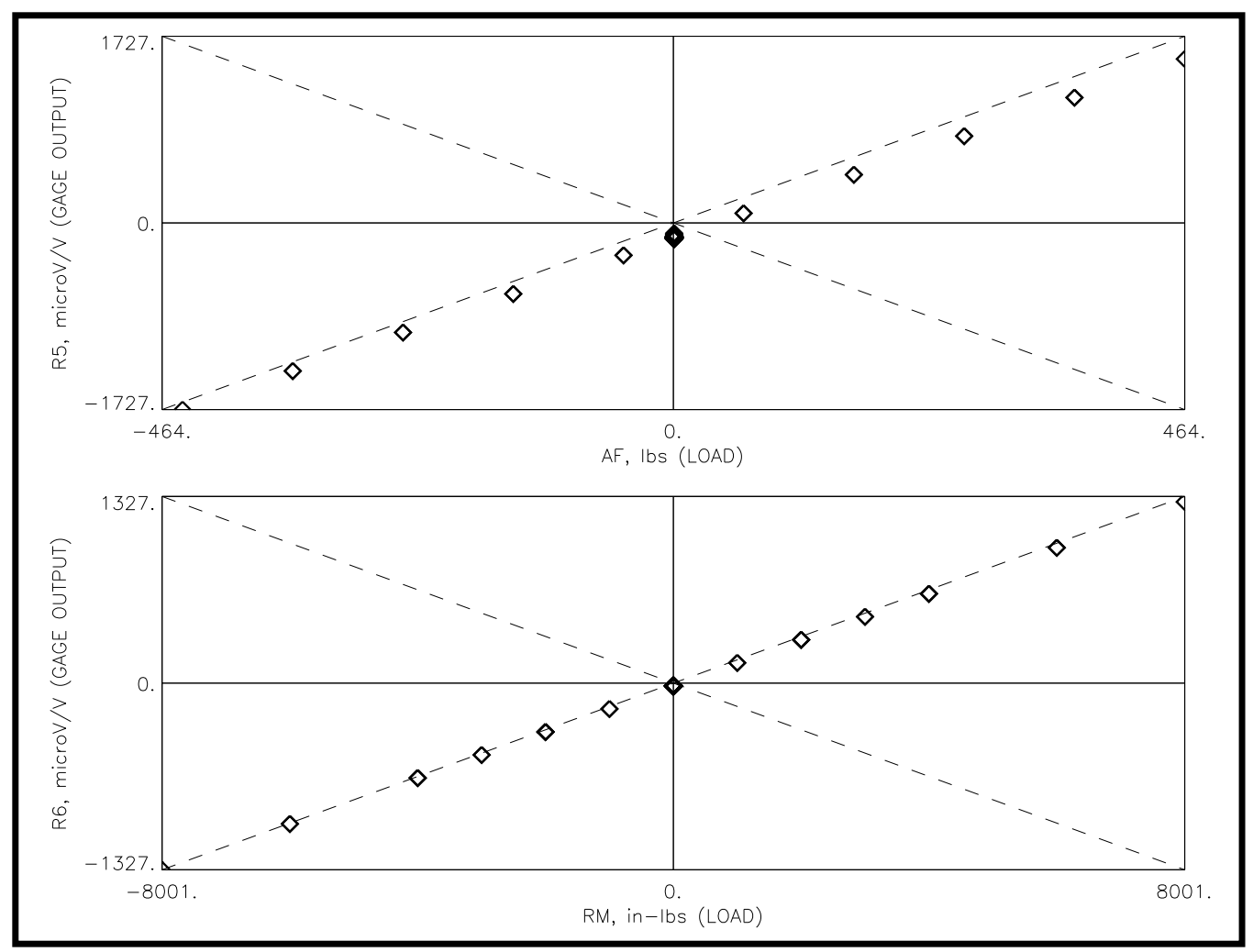

Fig. 6b Force Balance \& Direct-Read Format: Original gage outputs $R 5 \& R 6$ versus original loads $A F \& R M$. 


\begin{tabular}{|c|c|c|c|c|c|c|c|}
\hline INDEX & TERM & R1 & R2 & R3 & R4 & R5 & R6 \\
\hline 1 & INTERCEPT & $-1.923063 \mathrm{e}+01$ & $-1.973423 e+00$ & $-1.308814 e+00$ & $-5.689528 \mathrm{e}+01$ & $-1.387505 e+02$ & $-1.968715 e+01$ \\
\hline 2 & NF & $+1.689682 \mathrm{e}-01$ & $+1.669358 \mathrm{e}-01$ & $+3.741031 \mathrm{e}-03$ & $+9.008265 e-04$ & $+9.371567 e-04$ & $-2.435714 e-04$ \\
\hline & PM & $+3.93376 \mathrm{e}-02$ & $-4.621877 e-02$ & $+5.795458 \mathrm{e}-04$ & $-2.067612 e-04$ & $+8.526572 \mathrm{e}-04$ & $+3.132696 \mathrm{e}-05$ \\
\hline & SF & $-2.97 \quad 3 e-04$ & $+2.028585 e-03$ & $+2.418163 e-01$ & $+2.409373 e-01$ & $+1.290166 \mathrm{e}-03$ & $+6.701177 e-05$ \\
\hline & YM & $-5.984,66 e-05$ & $+2.743114 \mathrm{e}-04$ & $+7.106641 \mathrm{e}-02$ & $-7.509816 e-02$ & $-1.198671 \mathrm{e}-03$ & $+1.191286 \mathrm{e}-04$ \\
\hline & Af & $-1.220 \quad 45 e-03$ & $-2.745794 e-03$ & $+1.047114 \mathrm{e}-03$ & $-1.333567 e-04$ & $+3.569029 e+00$ & $+1.309445 \mathrm{e}-02$ \\
\hline 7 & RM & $+5.565 \quad 16 \mathrm{e}-04$ & $-4.833982 e-04$ & $+3.806558 \mathrm{e}-03$ & $+4.305434 \mathrm{e}-03$ & $+2.991991 \mathrm{e}-03$ & $+1.636123 e-01$ \\
\hline 8 & INFI & $+2.20624 \mathrm{e}-03$ & $+2.107804 e-03$ & $-9.744 \overline{29} 4 \mathrm{e}-04$ & $-2.873691 \mathrm{e}-03$ & $-1.131185 e-03$ & $+4.265002 e-04$ \\
\hline 9 & & $18 e-05$ & $+7.249080 e-05$ & $-1.752966 e-04$ & $+2.287768 \mathrm{e}-04$ & $+8.767747 e-04$ & $-7.678147 e-05$ \\
\hline 10 & ISFI & $-1.506363 e-03$ & $-1.480724 \mathrm{e}-03$ & $+5.982275 e-03$ & $+6.297408 \mathrm{e}-03$ & $+1.690368 \mathrm{e}-03$ & $-3.502368 e-04$ \\
\hline 11 & $|Y M|$ & $-2.388871 e-05$ & $+8.646396 e-05$ & $-2.466859 e-04$ & $-3.510335 e-04$ & $-1.757340 e-05$ & $+3.026453 e-05$ \\
\hline 12 & |AF| & $+2.957633 \mathrm{e}-04$ & $+6.676157 e-04$ & $-9.651199 e-04$ & $-1.863093 e-03$ & $+4.512896 e-03$ & $-5.098529 e-04$ \\
\hline 13 & |RMI & $-1.085143 e-03$ & $-7.851357 e-04$ & $+3.465286 \mathrm{e}-03$ & $+1.686099 \mathrm{e}-03$ & $-7.996867 e-06$ & $+1.621312 \mathrm{e}-04$ \\
\hline 14 & $N F \cdot N F$ & $-1.750140 e-07$ & $-6.162162 e-08$ & $-4.064130 e-08$ & $+7.978635 e-07$ & $+1.669153 e-06$ & $-1.597791 e-07$ \\
\hline 15 & $P M \bullet P M$ & $+1.978314 \mathrm{e}-08$ & $+1.415075 e-08$ & $+7.884241 \mathrm{e}-09$ & $-1.827730 \mathrm{e}-08$ & $-1.221898 \mathrm{e}-07$ & $+8.912752 \mathrm{e}-09$ \\
\hline 16 & $S F \cdot S F$ & $+3.358821 \mathrm{e}-07$ & $+3.665262 e-07$ & $-1.503459 e-07$ & $+1.407870 e-07$ & $-4,983421 e-07$ & $+8.599738 \mathrm{e}-08$ \\
\hline 17 & $Y M \cdot Y M$ & $+2.296277 \mathrm{e}-09$ & $-1.319246 e-08$ & $+6.716484 e-08$ & $+8.864099 \mathrm{e}-08$ & $-7.000575 e-08$ & $-3.216691 \mathrm{e}-09$ \\
\hline 18 & $A F \bullet A F$ & $-1.399947 e-07$ & $-4.007118 e-07$ & $+1.391601 e-07$ & $-4.439741 e-07$ & $-7.789509 e-06$ & $+9.626368 \mathrm{e}-07$ \\
\hline 19 & $R M \bullet R M$ & $+5.691378 \mathrm{e}-08$ & $+2.728383 e-08$ & $-2.844526 e-07$ & $-1.202040 \mathrm{e}-07$ & $+2.806873 e-07$ & $-1.478096 e-08$ \\
\hline 20 & $N F \cdot|N F|$ & 0 & 0 & 0 & 0 & 0 & 0 \\
\hline 21 & PM.|PM| & 0 & 0 & 0 & 0 & 0 & 0 \\
\hline$\cdots$ & $\cdots$ & $\cdots$ & $\cdots$ & $\cdots$ & $\cdots$ & $\cdots$ & $\cdots$ \\
\hline
\end{tabular}

Fig. 7a Direct-Read Format: Regression coefficient matrix of gage outputs $R 1$ to $R 6$.

\begin{tabular}{|c|c|c|c|c|c|c|c|}
\hline INDEX & TERM & R1 & R2 & R3 & R4 & R5 & R6 \\
\hline 1 & INTERCEPT & $-1.63 \%$ & $+0.27 \%$ & $-0.11 \%$ & $+8.66 \%$ & $-9.72 \%$ & $-1.50 \%$ \\
\hline 2 & NF & $+100.00 \%$ & $-160.53 \%$ & $+2.17 \%$ & $-0.96 \%$ & $+0.46 \%$ & $-0.13 \%$ \\
\hline 3 & PM & $+52.38 \%$ & $+100.00 \%$ & $+0.75 \%$ & $+0.50 \%$ & $+0.94 \%$ & $+0.04 \%$ \\
\hline 4 & SF & $-0.13 \%$ & $-1.39 \%$ & $+100.00 \%$ & $-183.33 \%$ & $+0.45 \%$ & $+0.03 \%$ \\
\hline 5 & YM & $-0.04 \%$ & $-0.33 \%$ & $+51.43 \%$ & $+100.00 \%$ & $-0.73 \%$ & $+0.08 \%$ \\
\hline 6 & AF & $-0.04 \%$ & $+0.15 \%$ & $+0.03 \%$ & $+0.01 \%$ & $+100.00 \%$ & $+0.40 \%$ \\
\hline 7 & RM & $+0.38 \%$ & $+0.53 \%$ & $+2.52 \%$ & $-5.24 \%$ & $+1.68 \%$ & $+100.00 \%$ \\
\hline 8 & INFI & $+1.31 \%$ & $-2.03 \%$ & $-0.56 \%$ & $+3.06 \%$ & $-0.55 \%$ & $+0.23 \%$ \\
\hline 9 & IPMI & $-0.06 \%$ & $-0.16 \%$ & $-0.23 \%$ & $-0.55 \%$ & $+0.97 \%$ & $-0.09 \%$ \\
\hline 10 & ISFI & $-0.64 \%$ & $+1.02 \%$ & $+2.47 \%$ & $-4.79 \%$ & $+0.59 \%$ & $-0.13 \%$ \\
\hline 11 & |YMI & $-0.02 \%$ & $-0.10 \%$ & $-0.18 \%$ & $+0.47 \%$ & $-0.01 \%$ & $+0.02 \%$ \\
\hline 12 & IAFI & $+0.01 \%$ & $-0.04 \%$ & $-0.03 \%$ & $+0.11 \%$ & $+0.13 \%$ & $-0.02 \%$ \\
\hline 13 & IRMI & $-0.73 \%$ & $+0.86 \%$ & $+2.29 \%$ & $-2.05 \%$ & $-4.48 e-03 \%$ & $+0.10 \%$ \\
\hline 14 & $\mathrm{NF} \cdot \mathrm{NF}$ & $-0.73 \%$ & $+0.41 \%$ & $-0.16 \%$ & $-5.95 \%$ & $+5.73 \%$ & $-0.60 \%$ \\
\hline 15 & $P M \bullet P M$ & $+0.41 \%$ & $-0.48 \%$ & $+0.16 \%$ & $+0.69 \%$ & $-2.12 \%$ & $+0.17 \%$ \\
\hline 16 & $\mathrm{SF} \cdot \mathrm{SF}$ & $+0.71 \%$ & $-1.26 \%$ & $-0.31 \%$ & $-0.54 \%$ & $-0.87 \%$ & $+0.16 \%$ \\
\hline 17 & $Y M * Y M$ & $+0.01 \%$ & $+0.14 \%$ & $+0.43 \%$ & $-1.03 \%$ & $-0.38 \%$ & $-0.02 \%$ \\
\hline 18 & $A F \bullet A F$ & $-1.89 e-03 \%$ & $+0.01 \%$ & $+1.84 \mathrm{e}-03 \%$ & $+0.01 \%$ & $-0.09 \%$ & $+0.01 \%$ \\
\hline 19 & $R M \bullet R M$ & $+0.31 \%$ & $-0.24 \%$ & $-1.51 \%$ & $+1.17 \%$ & $+1.26 \%$ & $-0.07 \%$ \\
\hline 20 & NF* INFI & 0 & 0 & 0 & 0 & 0 & 0 \\
\hline 21 & PM.|PMI & 0 & 0 & 0 & 0 & 0 & 0 \\
\hline$\cdots$ & . & $\cdots$ & $\cdots$ & $\cdots$ & $\cdots$ & $\cdots$ & $\cdots$ \\
\hline
\end{tabular}

Fig. 7b Direct-Read Format: Percent contribution of regression coefficients of gage outputs.

American Institute of Aeronautics and Astronautics 


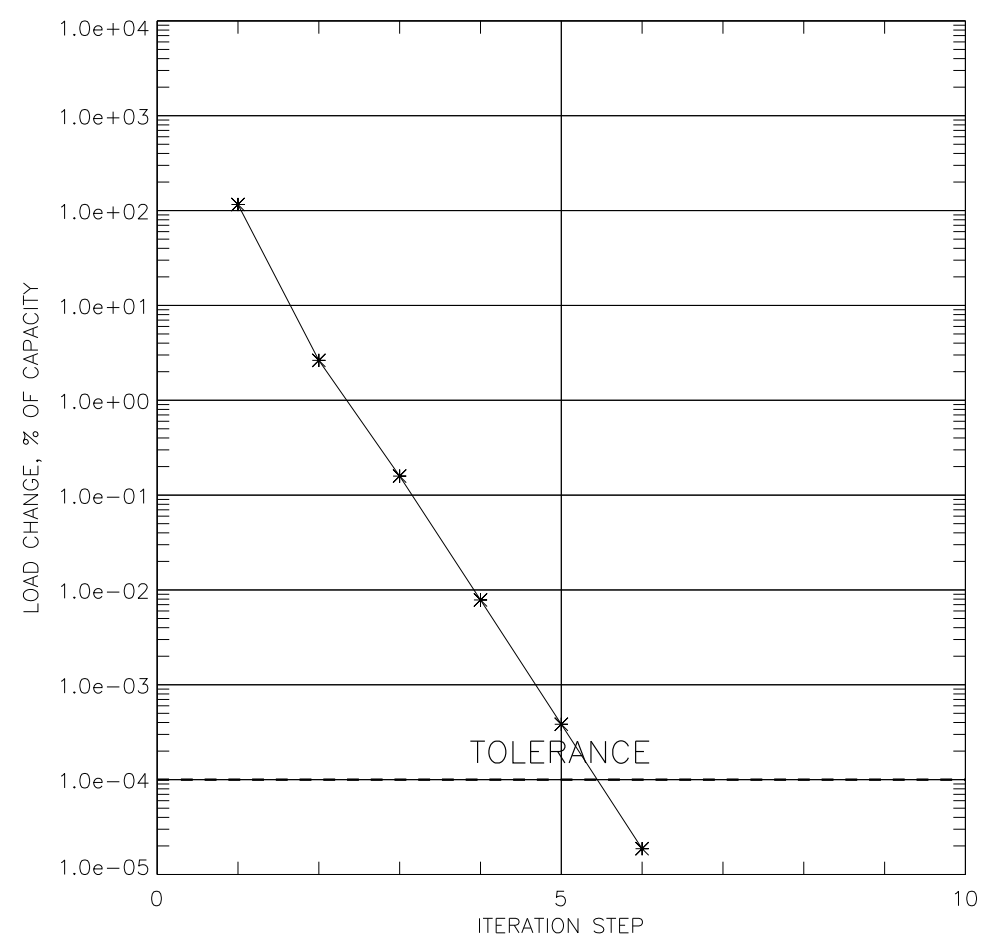

Fig. 8a Direct-Read Format: Iteration result for Primary Load Iteration Method (Eq. (1)).

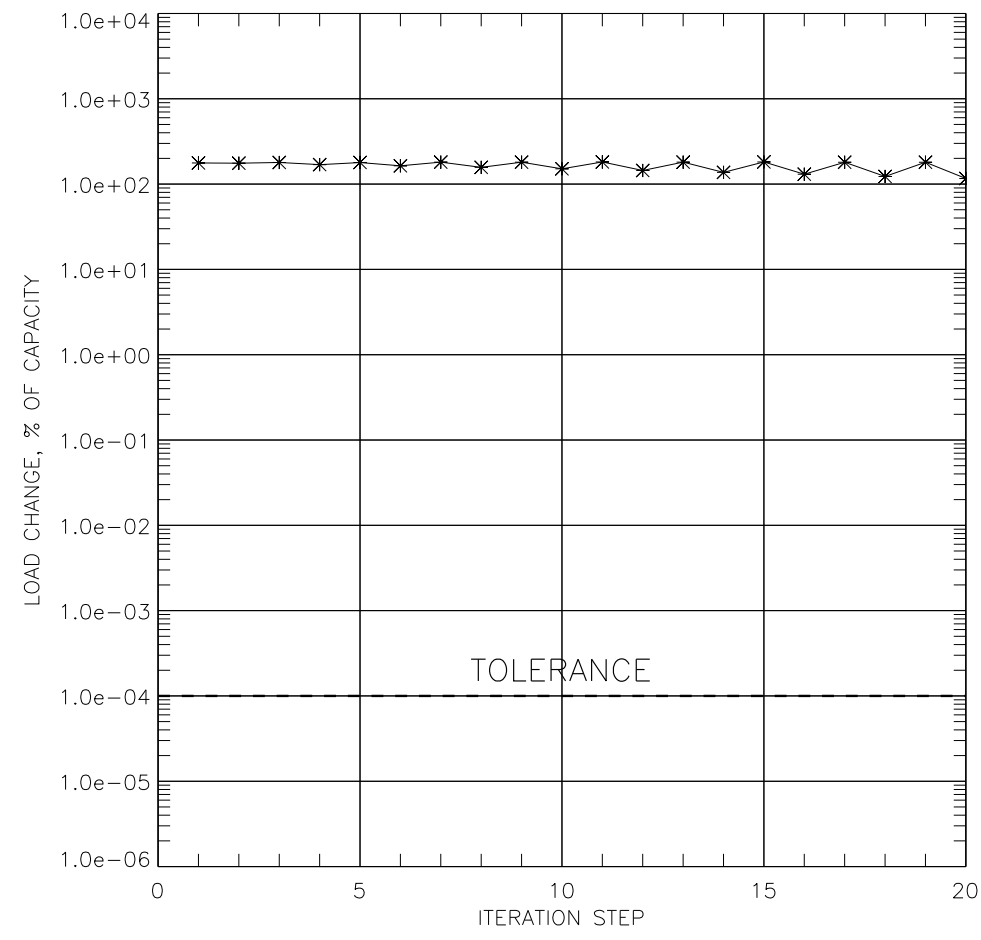

Fig. 8b Direct-Read Format: Iteration result for Alternate Load Iteration Method (Eq. (2)). 


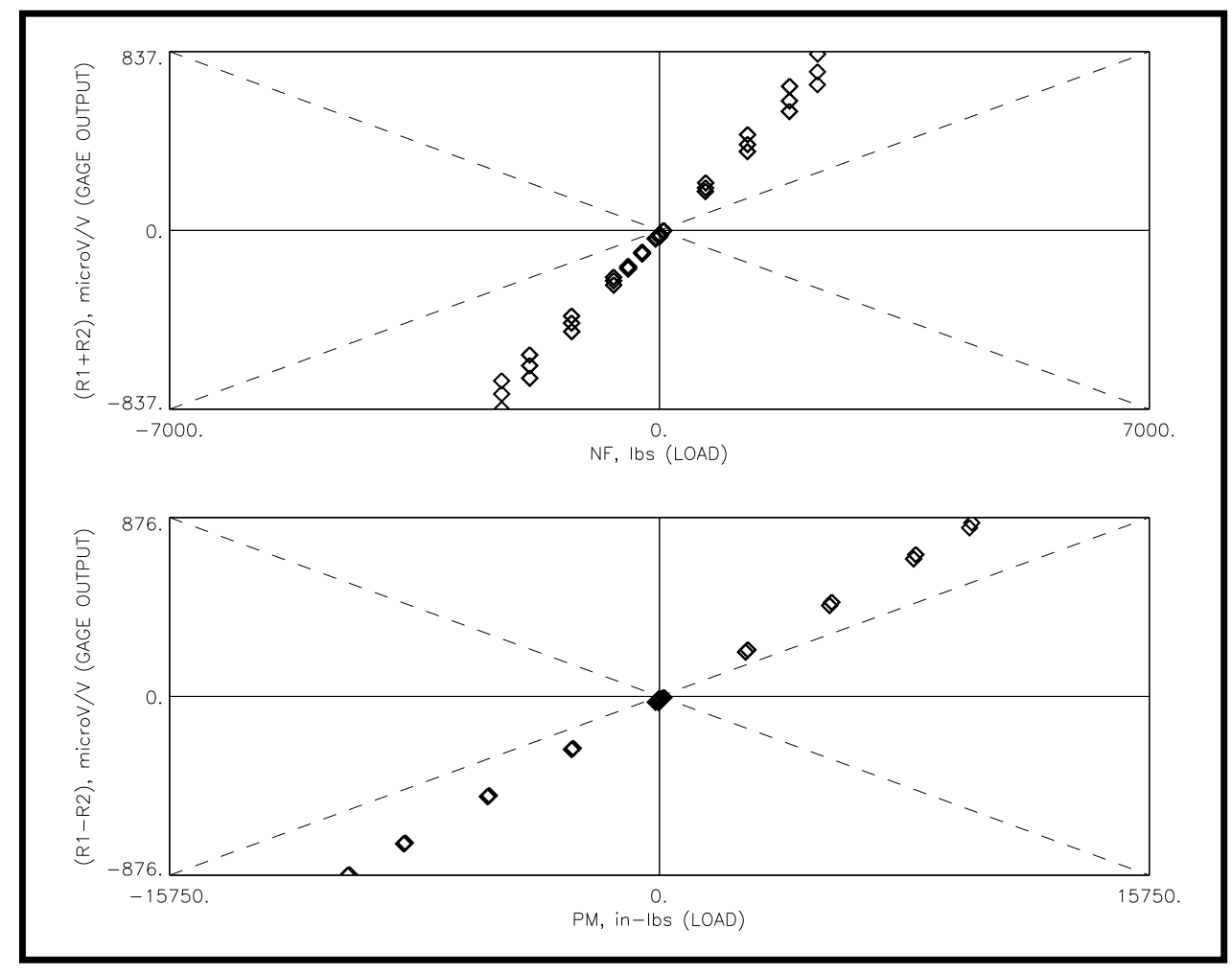

Fig. 9a Direct-Read Format: Transformed gage outputs $R 1+R 2$ and $R 1-R 2$ versus transformed loads $N F \& P M$.

\begin{tabular}{|c|c|c|c|c|c|c|c|}
\hline INDEX & TERM & $(\mathrm{R} 1+\mathrm{R} 2)$ & $(R 1-R 2)$ & $(R 3+R 4)$ & (R3-R4) & R5 & R6 \\
\hline 1 & INTERCEPT & $-0.90 \%$ & $-1.28 \%$ & $-2.41 \%$ & $+4.35 \%$ & $-9.72 \%$ & $-1.50 \%$ \\
\hline 2 & $\mathrm{NF}$ & $+100.00 \%$ & $+1.06 \%$ & $+1.35 \%$ & $+1.55 \%$ & $+0.46 \%$ & $-0.13 \%$ \\
\hline 3 & PM & $-4.61 \%$ & $+100.00 \%$ & $+0.24 \%$ & $+0.97 \%$ & $+0.94 \%$ & $+0.04 \%$ \\
\hline 4 & SF & $+0.37 \%$ & $-0.86 \%$ & $+100.00 \%$ & $+0.34 \%$ & $+0.45 \%$ & $+0.03 \%$ \\
\hline 5 & YM & $+0.08 \%$ & $-0.22 \%$ & $-1.46 \%$ & $+100.00 \%$ & $-0.73 \%$ & $+0.08 \%$ \\
\hline 6 & AF & $-0.07 \%$ & $+0.05 \%$ & $+0.02 \%$ & $+0.04 \%$ & $+100.00 \%$ & $+0.40 \%$ \\
\hline 7 & RM & $+0.02 \%$ & $+0.62 \%$ & $+2.69 \%$ & $-0.31 \%$ & $+1.68 \%$ & $+100.00 \%$ \\
\hline 8 & $|N F|$ & $+1.28 \%$ & $+0.05 \%$ & $-1.12 \%$ & $+1.04 \%$ & $-0.55 \%$ & $+0.23 \%$ \\
\hline 9 & IPMI & $+0.02 \%$ & $-0.14 \%$ & $+0.04 \%$ & $-0.50 \%$ & $+0.97 \%$ & $-0.09 \%$ \\
\hline 10 & ISFI & $-0.64 \%$ & $-0.01 \%$ & $+2.54 \%$ & $-0.12 \%$ & $+0.59 \%$ & $-0.13 \%$ \\
\hline 11 & |YMI & $+0.02 \%$ & $-0.07 \%$ & $-0.22 \%$ & $+0.07 \%$ & $-0.01 \%$ & $+0.02 \%$ \\
\hline 12 & $|A F|$ & $+0.02 \%$ & $-0.01 \%$ & $-0.05 \%$ & $+0.03 \%$ & $+0.13 \%$ & $-0.02 \%$ \\
\hline 13 & |RMI & $-0.64 \%$ & $-0.18 \%$ & $+1.71 \%$ & $+1.11 \%$ & $-4.48 e-03 \%$ & $+0.10 \%$ \\
\hline 14 & $N F * N F$ & $-0.49 \%$ & $-0.41 \%$ & $+1.54 \%$ & $-3.21 \%$ & $+5.73 \%$ & $-0.60 \%$ \\
\hline 15 & $P M * P M$ & $+0.36 \%$ & $+0.10 \%$ & $-0.11 \%$ & $+0.51 \%$ & $-2.12 \%$ & $+0.17 \%$ \\
\hline 16 & $\mathrm{SF} * \mathrm{SF}$ & $+0.75 \%$ & $-0.06 \%$ & $-0.01 \%$ & $-0.57 \%$ & $-0.87 \%$ & $+0.16 \%$ \\
\hline 17 & $Y M * Y M$ & $-0.04 \%$ & $+0.09 \%$ & $+0.50 \%$ & $-0.13 \%$ & $-0.38 \%$ & $-0.02 \%$ \\
\hline 18 & $A F * A F$ & $-3.68 e-03 \%$ & $+3.03 e-03 \%$ & $-1.90 e-03 \%$ & $+0.01 \%$ & $-0.09 \%$ & $+0.01 \%$ \\
\hline 19 & $R M * R M$ & $+0.23 \%$ & $+0.14 \%$ & $-1.07 \%$ & $-0.82 \%$ & $+1.26 \%$ & $-0.07 \%$ \\
\hline 20 & $N F *|N F|$ & 0 & 0 & 0 & 0 & 0 & 0 \\
\hline 21 & PM*IPMI & 0 & 0 & 0 & 0 & 0 & 0 \\
\hline$\cdots$ & $\cdots$ & $\cdots$ & $\cdots$ & $\cdots$ & $\cdots$ & $\cdots$ & $\cdots$ \\
\hline
\end{tabular}

Fig. 9b Direct-Read Format: Percent contribution of regression coefficients of transformed gage outputs. 


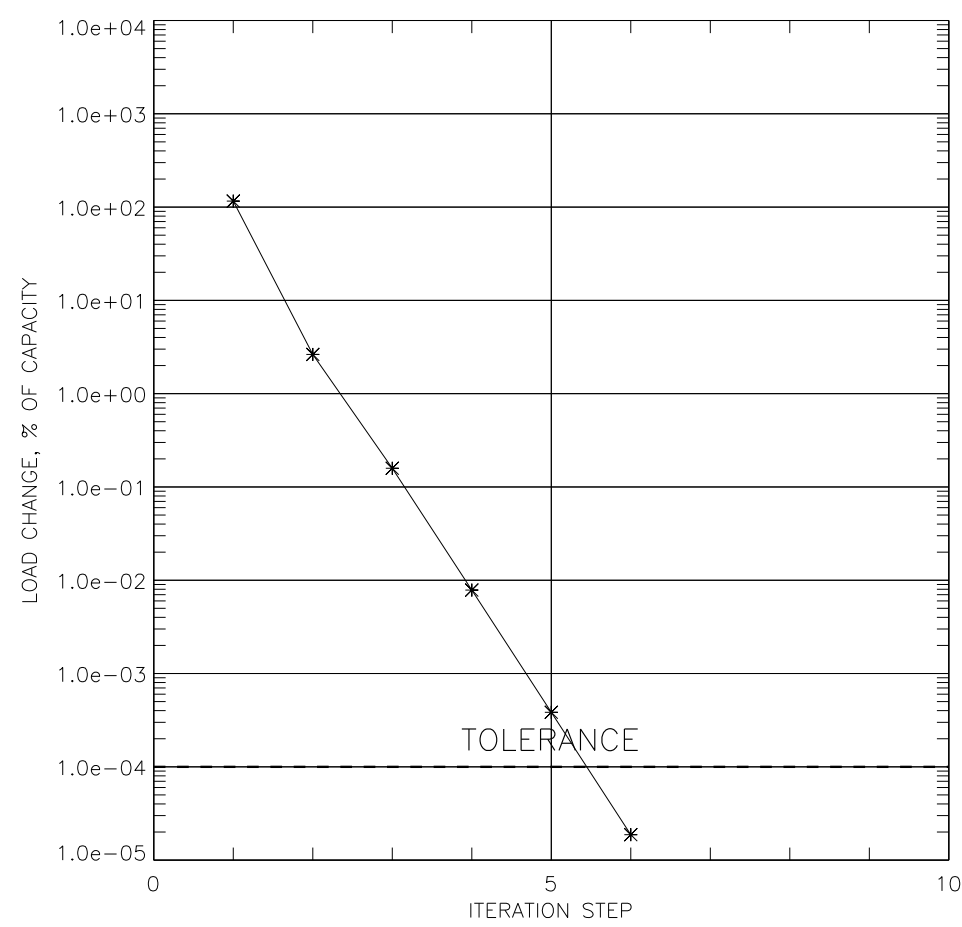

Fig. 10a Direct-Read Format \& Transf. Outputs: Iteration result for Primary Load Iteration Method (Eq. (1)).

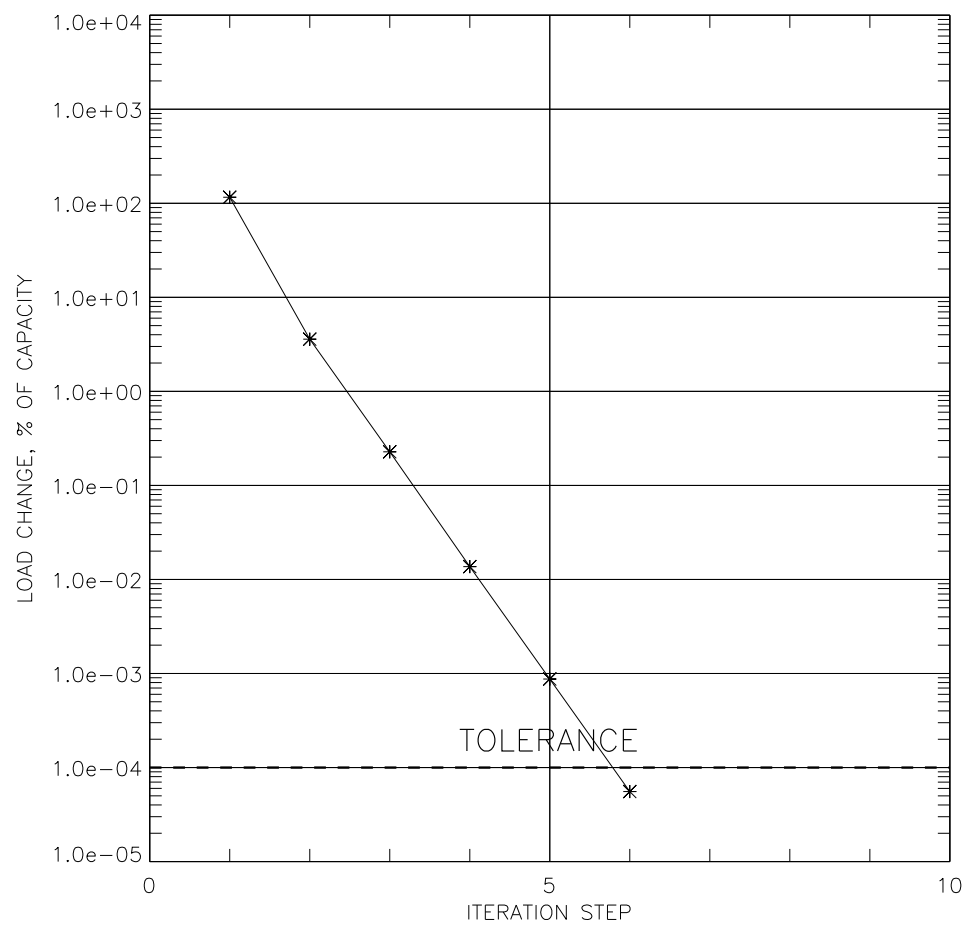

Fig. 10b Direct-Read Format \& Transf. Outputs: Iteration result for Alternate Load Iteration Method (Eq. (2)). 